American Journal of Applied Sciences 6 (9): 1647-1652, 2009

ISSN 1546-9239

(C) 2009 Science Publications

\title{
Characterization of Bio-Oil: A By-Product from Slow Pyrolysis of Oil Palm Empty Fruit Bunches
}

\author{
${ }^{1}$ K.H. Khor, ${ }^{1}$ K.O. Lim and ${ }^{2}$ Z.A. Zainal \\ ${ }^{1}$ School of Physics, \\ University Sains Malaysia, Minden, 11800 Pulau Pinang, Malaysia \\ ${ }^{2}$ School of Mechanical Engineering, Engineering Campus, \\ University Sains Malaysia, 14300 Nibong Tebal, Penang, Malaysia
}

\begin{abstract}
Problem Statement: Oil palm Empty Fruit Bunches (EFB) are abundant biomass in Malaysia. Studies about production of biofuels using slow pyrolysis of EFB are still lacking. So, this study was aimed to understand the physical and chemical properties of the bio-oil and its simple blends. Approach: EFB was slow pyrolysed with internal heating at terminal temperature of $600^{\circ} \mathrm{C}$ in a pilot kiln and the main product is the EFB char and the condensates from the emissions were separated into aqueous and tarry fractions. Results: $13 \mathrm{wt} \%$ of tarry component (referred as EFB oil) was obtained as small fraction of co-product. The chemical composition of the EFB oil acquired was analyzed by GC-MS and its elemental composition, stability, miscibility, oil fuel properties and corrosion characteristics were determined. The empirical formula of the EFB oil with heating value of $31.44 \mathrm{MJ} \mathrm{kg}^{-1}$ was established as $\mathrm{CH}_{1.41} \mathrm{~N}_{0.03} \mathrm{O}_{0.24}$. Characterizations of bio-oil, diesel and emulsifier blends were performed. Conclusions/Recommendations: The experimental results showed that the emulsions of EFB oil obtained may be directly used as a fuel oil for combustion in a boiler or a furnace without any upgrading. Alternatively, the fuel may be refined to be used by vehicles.
\end{abstract}

Key words: Biomass, EFB, pyrolysis, EFB oil

\section{INTRODUCTION}

Biomass is widely considered as a sustainable source of renewable energy particularly in countries where there is plentiful agricultural activities. Over the last two decades, special attention has been paid to conversion of residual biomass and renewable materials into bio-oil. Bio-oil is renewable and biodegradable. Moreover, it does not contribute to a net rise in the level of $\mathrm{CO}_{2}$ in the atmosphere and, consequently, to the greenhouse effect ${ }^{[1]}$.

Oil palm empty fruit bunches (EFB) are abundant in Malaysia with an annual production of more than 18 million tons (fresh $\mathrm{wt})^{[2]}$. Traditional methods such as composting and incineration are not suitable to process these organic solid wastes, as they contain small concentrations of nitrogen for composting and a considerable amount of solid grains and smoke would be released to pollute the environment during incineration. Therefore, a practical method should be to pyrolyse EFB for providing char, EFB vinegar and biooil.
Currently, the potential of biomass energy usually derives from forest residues, agricultural residues and aquatic plant. For example, Das et al. ${ }^{[3]}$ pyrolysed cashew nut shells in a fixed bed under vacuum and Abdullah et al..$^{[4]}$ had carried out a series of fast pyrolysis experiments on washed EFB have been performed using a $150 \mathrm{~g} \mathrm{~h}^{-1}$ fluidized bed reactor operating at atmospheric pressure. There are many reports on fast pyrolysis of biomass for bio-oil production which needed a high cost of energy input. But for this study, slow pyrolysis of EFB with external heating was used with the non-condensable gases recycled as additional fuel. The collected bio-oil by condensation process was in small percentage whereas bio-char was the main product.

Bio-oil is a polar and high density oxygenated liquid that can be used as a substitute for liquid fossil fuels in some applications. It can be burned in diesel engines, boilers, turbines for electricity generation, though further work is still required to demonstrate long term reliability. It may also be used for the production of special chemicals, mainly flavorings. Renewable

Corresponding Author: K.H. Khor, Bioenergy Laboratory, School of Physics, University Sains Malaysia, Minden, 11800 Pulau Pinang, Malaysia. 
resins and slow release fertilizers are other potential applications, which have been the subject of research ${ }^{[5]}$.

A laboratory-scale study of slow pyrolysis of $\mathrm{EFB}^{[6]}$ was developed at the University Sains Malaysia and further investigation using a pilot kiln was reported by K.H. Khor et al. ${ }^{[7]}$ The quality of EFB char produced was analyzed and the chemical constituents of EFB vinegar were identified by GC-MS. Presently, there are no systematical research reported about the properties of bio-oil, a co-product from slow pyrolysis of EFB. Hence, this research is the extension to that study.

\section{MATERIALS AND METHODS}

Raw material: EFB constitutes about 20 to $22 \%$ of the weight of fresh fruit bunches and contains $30.5 \%$ dry matter, $2.5 \%$ oil and $67 \%$ water ${ }^{[8]}$. Prior to use, the fresh EFB (Fig. 1) should be processed into fibers (Fig. 2) by removing water and some oil. According to Szetech Engineering procedures ${ }^{[9]}$, the EFB were high speed hammer milled, broken, pressed and size reduced.

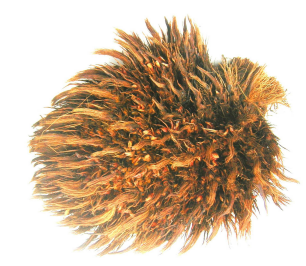

Fig. 1: A fresh EFB

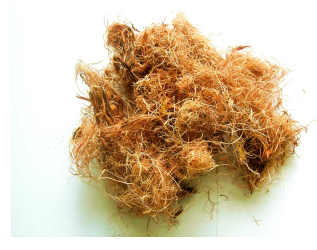

Fig. 2: EFB fibers

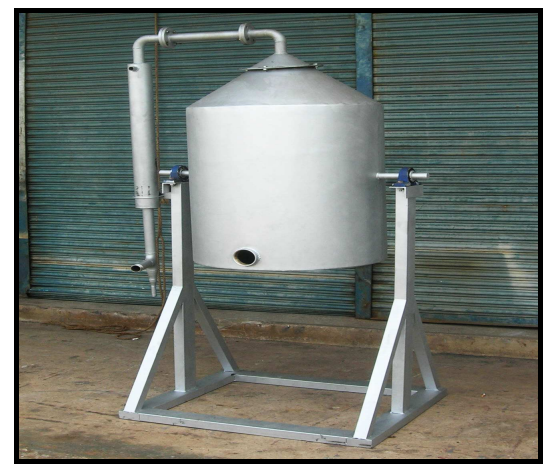

Fig. 3: A pilot kiln was fabricated for slow pyrolysis of EFB
Pyrolysis process and methods: Slow pyrolysis of the EFB was carried out using a pilot kiln (Fig. 3). The pyrolyser is basically a cylindrical mild-steel container with cone shape cover on the top. This sample holder has a length of $114 \mathrm{~cm}$ and an internal diameter of 76 $\mathrm{cm}$. The EFB fibers were heated internally with initial partial burning at the bottom part of chamber which was ignited using the liquefied petroleum gas (LPG) fire below the wire mesh with the help of a blower. The kiln temperatures were measured by the thermocouples at 3 different positions. The pyrolysis experiments were performed with bales of dry EFB packed inside the pyrolyser. The emissions of the pyrolysis process were recovered using a stainless-steel condenser.

The weights of raw EFB fibers that were packed into the carbonization chamber of the pilot kiln for each of the 3 pyrolysis runs were found to be about $100 \mathrm{~kg}$. As the biomass was heated up, the initial stage involved the removal of moisture from the EFB fibers at temperatures of less than $110^{\circ} \mathrm{C}$. As the experiment proceeded, devolatilisation was initiated at about $240^{\circ} \mathrm{C}$ and was complete by about $600^{\circ} \mathrm{C}$. The release of white volatiles was observed to end after $2 \mathrm{~h}$ when the heating rate of about $5^{\circ} \mathrm{C} \mathrm{min}{ }^{-1}$ was applied. The condensates collected in the ice-cooled container were found to consist of a rather viscous black tarry component floating in a fairly clear brownish solution but on standing, this tarry component eventually precipitated to the base and the wall of the container. Therefore, there was a separation of 2 distinct fractions: one of viscous tar labeled as EFB oil and the other of a less oily brownish aqueous phase is referred to as EFB vinegar.

In our study when EFB fibers were pyrolysed, the main product, $24.8 \%$ of EFB char was yielded, with $62.3 \%$ of condensates as by-products. The quality of EFB char and the identification of chemical compounds in EFB vinegar were presented in previous report ${ }^{[7]}$. The EFB oil produced was only $12.9 \%$ and their characterizations were performed by various analyses for their physical properties, chemical compositions, stability, miscibility, fuel oil properties and corrosion characteristics using ASTM and ISO standard test methods.

Blending EFB oil and Malaysian diesel: This blending process is based on the production of a stable emulsion between EFB oil and conventional diesel oil. The EFB oil and diesel blend is a two-phase system due to diesel oil and EFB oil are not miscible; therefore an emulsifier (or surfactant), Hypermer B246SF has to be added to obtain a stable emulsion to change the 
interfacial properties of the system and avoid or delay the breaking of the emulsion. It was diluted by methanol at a ratio of 2:5 (v/v) emulsifier to methanol.

Five different ratios (w/w) of blend, ranging from $5-75 \%$ of EFB oil with diesel, were prepared and $5 \%$ of emulsifier dilution was introduced into each mixture using syringe. The stable emulsions were formed after stirring for $6 \mathrm{~h}$ using a magnetic stirrer. Once again, their characterizations were performed by various analyses for their chemical compositions, fuel oil properties and corrosion characteristics using ASTM and ISO standard test methods.

\section{RESULTS}

Knowledge of the physical and chemical characteristics of raw materials is essential for optimizing the efficiency of any thermochemical conversion process. The proximate analysis, elemental composition, gross calorific value and chemical analysis of the raw EFB fibers were conducted and shown in Table 1.

Table 1: Composition of the raw EFB fibers

\begin{tabular}{lr}
\hline Proximate analysis (wt\% ar) & \\
Moisture & 8.65 \\
Volatile & 75.09 \\
Ash & 3.92 \\
Fixed carbon & 12.34 \\
Higher calorific value $\left(\mathrm{MJ} \mathrm{kg}^{-1}\right)$ & 18.66 \\
Elemental analysis (wt \% daf) & \\
Carbon & 43.21 \\
Hydrogen & 7.42 \\
Nitrogen & 0.86 \\
Sulphur & 0.75 \\
Oxygen (by difference) & 47.76 \\
Chemical analysis $(\mathbf{w t} \% \mathbf{m f})$ & \\
Hemicelluloses & 33.52 \\
Cellulose & 38.52 \\
Lignin & 20.36 \\
Extractives & 3.68 \\
Ash & 3.92 \\
\hline
\end{tabular}

Table 2: Main properties and elements of EFB oil. The results shown are the average from 3 runs

\begin{tabular}{|c|c|c|}
\hline Properties & Method & EFB Oil \\
\hline Color & Visual & Black \\
\hline Odor & Smell & Acrid smoky \\
\hline $\mathrm{pH}$ & $\mathrm{pH}$ meter & 3.6 \\
\hline Water content & ASTM D-4928 & $5.2 \%$ \\
\hline Acidity, mg KOH g ${ }^{-1}$ & ASTM D-664 & $102.9 \mathrm{~g}$ \\
\hline $\mathrm{C}$ & ASTM D-5373 & $68.26 \%$ \\
\hline $\mathrm{H}$ & ASTM D-5373 & $8.02 \%$ \\
\hline $\mathrm{N}$ & ASTM D-5373 & $2.02 \%$ \\
\hline $\mathrm{S}$ & ASTM D-4294 & $0.03 \%$ \\
\hline Ash & ASTM D-482 & $0.10 \%$ \\
\hline $\mathrm{O}$ & By difference & $21.57 \%$ \\
\hline Empirical formula & Molar ratio & $\mathrm{CH}_{1.41} \mathrm{~N}_{0.03} \mathrm{O}_{0.24}$ \\
\hline Higher calorific value & ASTM D-5865 & $31.44 \mathrm{MJ} \mathrm{kg}^{-1}$ \\
\hline
\end{tabular}

The proximate analysis shows that raw EFB fibers have a rather high volatile content, a medium level of ash content and a rather low fixed carbon content, but the elemental analysis indicates that raw EFB fibers are environment friendly, with trace amounts of nitrogen and sulphur. Their chemical compositions were not much different from any wood specie. Their inherent moisture contents are minimum and much less than the unprocessed fresh EFB so that they can be pyrolysed easily.

The properties and compositions of the EFB oil: The EFB oil from our process is dark viscous liquid and not homogeneous. If left standing for long periods, the high-molecular weight tar, mostly from lignin, may further become a gum and ultimately a carbonaceous clot. It will eventually precipitate, however it can be stirred back into the bulk with slow-speed agitation. The physico-chemical properties of EFB oil are shown in Table 2.

From Table 2 it can be found that the bio-oil contains small concentrations of $\mathrm{S}, \mathrm{N}$ and other pollutant base.

The compositions of EFB oil was analyzed with gas chromatography-mass spectrometry. The identified chemical compounds of EFB oil is shown in Table 3.

From the result of GC-MS analyses, it can be concluded that the EFB oil is extremely complex and may be composed of numerous of organic compounds. The main components of the bio-oil include acids, phenols, ester, ketones, alkenes and some species of aromatics, which are in accordance with those obtained from the fast pyrolysis of woods. The presence of these aromatic and oxygenated compounds is attributable to its biopolymer textures such as cellulose and hemicellulose. Obviously, the highly oxygenated organic components would need to be first separated from the aqueous phase and then upgraded using hydrotreating-hydrocracking process in order to further raise their heating values and reduce the corrosiveness when they are used as a potential fuel ${ }^{[10]}$. Upgrading bio-oil into transportation fuel is feasible but currently not economic.

The information in Table 2 and 3 indicates that the EFB oil is a complicated organic compound that mainly consists of water, acids and heterocyclic substances. Furthermore the energy density of the bio-oil is much higher than that of the EFB so it is convenient for transportation and utilization.

Stability characteristics of EFB oil: There were clear differences in combustibility and emissions for different oil grades. The most important parameters for bio-oil combustion are viscosity, water and particulates content, ratio of emulsion, raw material and ageing. 
Am. J. Applied Sci., 6 (9): 1647-1652, 2009

Table 3: Compositions of EFB oil

\begin{tabular}{lc}
\hline Chemical compound & Relative $(\%)$ \\
\hline Phenol & 11.68 \\
2-methyl-phenol & 1.71 \\
4-methyl-phenol & 4.77 \\
3, 5-dimethyl-phenol & 0.97 \\
2-methoxy-4-methyl-phenol & 3.08 \\
2-methoxy-benzeneethanol & 3.20 \\
Tridecane & 0.53 \\
Decanoic acid, methyl ester & 0.42 \\
2, 6-dimethoxy-phenol & 2.52 \\
2-methoxy-4-propyl-phenol & 1.29 \\
1-Tetradecene & 1.33 \\
Decanoic acid & 1.23 \\
2-methoxy-4-(1-propenyl)-phenol & 0.70 \\
Undecanenitrile & 0.88 \\
2-Tridecanone & 0.71 \\
Pentadecane & 1.11 \\
Dodecanoic acid, methyl ester & 5.16 \\
2,6-dimethoxy-4-(2-propenyl)-phenol & 0.85 \\
Dodecanoic acid & 30.92 \\
Tetradecanenitrile & 0.52 \\
8-Heptadecene & 1.73 \\
Heptadecene & 0.59 \\
Tetradecanoic acid, methyl ester & 2.46 \\
Tetradecanoic acid & 4.87 \\
Hexadecanoic acid, methyl ester & 2.25 \\
n-Hexadecanoic acid & 0.85 \\
9-Octadecanoic acid, methyl ester & 1.69 \\
8-Octadecanoic acid, methyl ester & 0.93 \\
Octadecanoic acid, methyl ester & 0.47 \\
Other compounds & 10.58 \\
\hline *: Obtained at heating rate of $5^{\circ} \mathrm{C}$ min $^{-1}$, pyrolysis temperature $600^{\circ} \mathrm{C}$ \\
and holding time of 2 h & \\
&
\end{tabular}

Viscosity of a liquid fuel plays an important role in design and operation of the fuel injection system, as well as on the atomization quality and subsequent combustion properties of the fuel. The change of viscosity of EFB oil at different storage conditions are shown in Fig. 4 and 5.

It is found that EFB oil's viscosity increases during storage at room temperature due to slow polymerization and condensation reactions. But the decrease of viscosity of EFB oil is enhanced by higher temperature and the rate of increase of viscosity of bio-oil is found to reduce after some time, hence bio-oil with certain instabilities affect the performance of EFB oil.

With the presence of some inhibitors, for example hydroquinone, the rate of increase of the viscosity of bio-oil can be dramatically reduced due to the suppression of thermal polymerization reactions by the inhibitors $^{[11]}$.

The change tendency of the viscosity of our EFB oil is similar to that of Das's report ${ }^{[3]}$, but there is more moisture content in EFB oil than in cashew nut shell bio-oil (3-4\%). Hence, the change of the viscosity of our bio-oil is faster than that of above report.

Corrosivity of the EFB oil: A corrosivity test of the EFB oil was performed to study the weight loss of copper and stainless steel for 5 days.

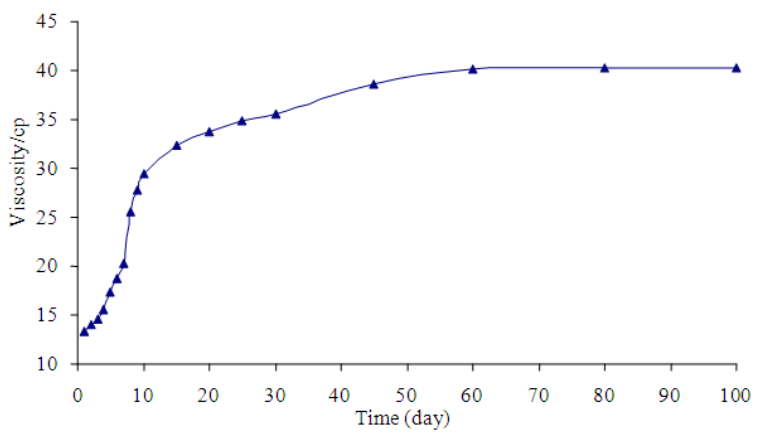

Fig. 4: Viscosity at $50^{\circ} \mathrm{C}$ versus time. The points shown are the average from 3 runs

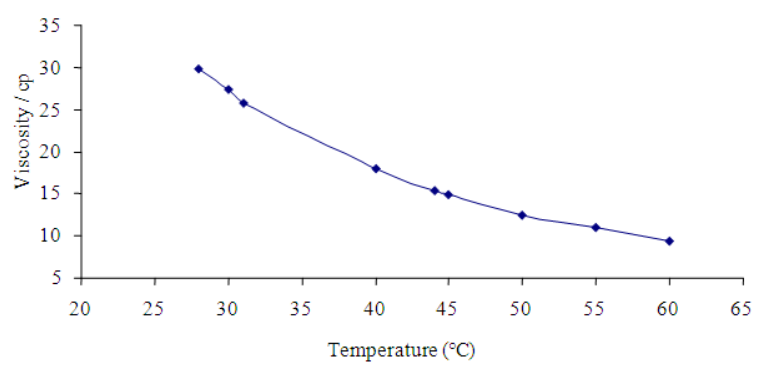

Fig. 5: Viscosity versus temperature. The points shown are the average from 3 runs

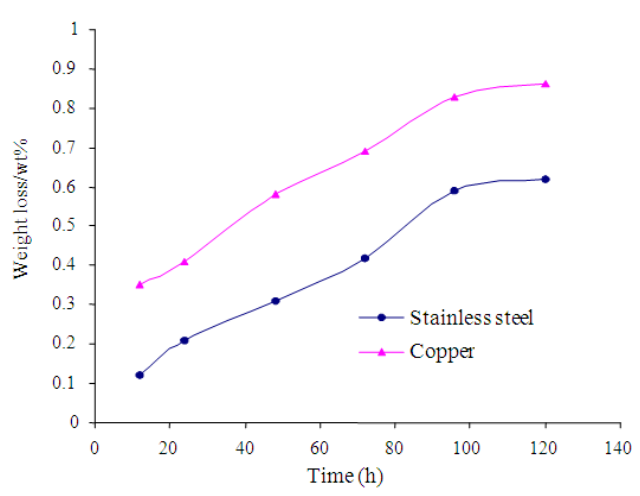

Fig. 6: Corrosivity of the EFB oil. The points shown are the average from 3 runs

EFB-oil comprises substantial amounts of carboxylic acids, which leads to low $\mathrm{pH}$ values of 3.6. The bio-oil of pine had a $\mathrm{pH}$ of 2.6, while that of hardwood was $2.8^{[12]}$. Acidity makes bio-oil very corrosive and extremely severe at elevated temperature, which imposes more requirements on construction materials of the vessels and the upgrading process before using bio-oil in transport fuels.

Fig. 6 shows the weight loss of the copper strip and stainless steel strip versus time for the EFB oil stored at $50^{\circ} \mathrm{C}$. 
Am. J. Applied Sci., 6 (9): 1647-1652, 2009

Table 4: Properties of emulsions. The results shown are the average from 3 runs

\begin{tabular}{|c|c|c|c|c|c|c|c|}
\hline Analysis & $\begin{array}{l}\text { Diesel } \\
100 \%\end{array}$ & $\begin{array}{l}\text { EFB oil } \\
100 \%\end{array}$ & $\begin{array}{l}\text { EFB oil } \\
75 \%\end{array}$ & $\begin{array}{l}\text { EFB oil } \\
50 \%\end{array}$ & $\begin{array}{l}\text { EFB oil } \\
25 \%\end{array}$ & $\begin{array}{l}\text { EFB oil } \\
10 \%\end{array}$ & $\begin{array}{l}\text { EFB oil } \\
5 \%\end{array}$ \\
\hline \multicolumn{8}{|l|}{ Elemental/wt\% } \\
\hline $\mathrm{C}$ & 86.52 & 68.26 & 72.23 & 76.35 & 80.54 & 83.61 & 84.98 \\
\hline $\mathrm{H}$ & 13.30 & 8.02 & 9.02 & 9.98 & 10.02 & 11.31 & 12.54 \\
\hline $\mathrm{N}$ & 0.04 & 2.02 & 1.87 & 1.23 & 0.97 & 0.42 & 0.18 \\
\hline $\mathrm{S}$ & 0.11 & 0.03 & 0.05 & 0.06 & 0.07 & 0.08 & 0.09 \\
\hline Ash & 0.00 & 0.10 & 0.08 & 0.06 & 0.05 & 0.04 & 0.03 \\
\hline $\mathrm{O}$ & 0.03 & 21.57 & 16.75 & 12.32 & 8.35 & 4.54 & 2.18 \\
\hline Kinematic viscosity @ $50^{\circ} \mathrm{C} / \mathrm{cSt}$ & 3.05 & 13.52 & 10.83 & 7.84 & 6.93 & 6.05 & 5.32 \\
\hline Density $/ \mathrm{g} \mathrm{cm}^{-3}$ & 0.853 & 1.031 & 1.028 & 0.995 & 0.967 & 0.905 & 0.897 \\
\hline $\mathrm{pH}$ value & Neutral & 3.6 & 3.7 & 4.1 & 4.6 & 4.8 & 5.2 \\
\hline Corrosion (Cu 3h@100) & Class 1a & Class $1 \mathrm{~b}$ & Class $1 \mathrm{~b}$ & Class $1 \mathrm{~b}$ & Class 1a & Class 1a & Class 1a \\
\hline Flash point $/{ }^{\circ} \mathrm{C}$ & 98 & 65 & 73 & 82 & 93 & 95 & 99 \\
\hline Pour point $/{ }^{\circ} \mathrm{C}$ & 15 & 12 & 12 & 13 & 13 & 14 & 14 \\
\hline Sediment/wt $\%$ & 0 & 0.2 & 0.2 & 0.2 & 0.2 & 0.1 & 0.1 \\
\hline $\mathrm{HHV} / \mathrm{MJ} \mathrm{kg}^{-1}$ & 45.80 & 31.44 & 34.23 & 36.64 & 39.32 & 41.23 & 43.20 \\
\hline
\end{tabular}

It is found that the $\mathrm{EFB}$ oil stored at $50^{\circ} \mathrm{C}$ results in a weight loss for both metals increased with time. Though, the corrosivity is higher for copper $(0.86 \mathrm{wt} \%$ loss) than the stainless steel strip (0.62wt\% loss) when kept in the EFB oil for $120 \mathrm{~h}$, respectively. Hence, the corrosivity of the EFB oil is very mild towards them.

The corrosivity of our EFB oil is comparable to that of Zheng's bio-oil from rice husk ${ }^{[1]}$, but is lower than that of Ikura's study ${ }^{[13]}$ because there is more organic acid in the hardwood bio-oil with $\mathrm{pH}$ of 2.37 .

Miscibility study of EFB oil with diesel: Our experimental results indicate that the EFB oil is immiscible in diesel and stratification forms when the EFB oil is directly blended with diesel. However, homogeneous emulsions are obtained when mixing the EFB oil and 5 wt $\%$ of diluted emulsifier, Hypermer B246SF with diesel in different ratios.

The physical properties of the emulsions are shown in Table 4 which shows the emulsions have higher carbon and hydrogen contents, $\mathrm{pH}$ value, pour point and HHV, but their ash and oxygen contents, density, viscosity, corrosion and flash point are lower than the pure EFB oil. However, it is possible to consider EFB oil emulsification as a possible and relatively short term approach to the direct use of the bio-oils in diesel engines, reducing the investment in upgrading technologies.

The change tendency of density, viscosity, flash point, heat value and $\mathrm{pH}$ of our bio-oil is comparable to that of Chiaramonti's report ${ }^{[14]}$. Emulsions with $5-25 \%$ EFB oil in diesel would improve fuel stability and viscosity, reduce corrosiveness and provide the properties similar to neat diesel. The lower the bio-oil content, the lower the viscosity of the emulsion. Furthermore the carbon content of these emulsions is still above $80 \%$ and the heating values maintain around $40 \mathrm{MJ} \mathrm{kg}^{-1}$.

\section{DISCUSSION}

The EFB oil is immiscible in Malaysian diesel oil. Mix the two and they formed two separated phases with plenty of sediment. Now an effective process for mixing them is available. Once mixed the two oils by addition of 5\% emulsifier, form a blend that is stable, non-corrosive and easy to ignite. Laboratory evaluation of bio-oil/diesel fuel mixtures is based on ASTM and ISO standard test methods. We produced a biooil/diesel fuel emulsion; especially emulsion of 5 to $25 \%$ EFB oil having properties about similar to those of conventional diesel fuels. Most boilers, turbines and power generation stations may use this blended fuel without major modifications. Most of the current research effort on utilization of bio-oil from fast pyrolysis of biomass is targeted at liquid fuel applications, which are only potentially viable, i.e. without subsidy, for certain waste feedstocks. In our slow pyrolysis of EFB with internal heating, the production of bio-oil is small but low cost in operation; it still may be utilized for the manufacture of chemicals, materials of higher added value and liquid fuels. Some of the applications may include production of specific chemical synthons, flavor chemicals, organic fertilizers, fuel additives, additives for pollution control, boiler fuels and diesel fuels. We envisage a biomass refinery, analogous to a petroleum refinery, but in which the distinctive character of bio-oil is recognized and it is refined into useful products.

\section{CONCLUSION}

The slow pyrolysis of EFB results in the production of mainly solid char, liquid and gaseous by-products. The liquid fraction of the pyrolysis products consists of 2 phases: An aqueous phase (EFB vinegar) containing a 
wide variety of organo-oxygen compounds of low molecular weight, and a tarry phase (EFB oil) containing insoluble organics of high molecular weight. Among the organic compounds, phenol is one of the most valuable products. The heating value of EFB oil was about $70 \%$ of the petroleum oil. It has experienced an increase in viscosity over 100 days storage, but decreased when the temperature raised. Blending diesel into the EFB oil, with the help of emulsifier, was proved to improve the properties and stability of the bio-oil where the viscosity was reduced and slowed down the aging process.

\section{ACKNOWLEDGEMENT}

The researchers wish to thank Malpom Industries Sdn Bhd, Nibong Tebal for the supply of EFB fibers and also Mr. Puad Elham and Mah Kok Foon for their help in some of the pyrolysis runs in FRIM, Kepong. We are also grateful to Croda Asia Pacific Sdn Bhd, Petaling Jaya for the supply of emulsifier and ITS Testing Services (M) Sdn Bhd, Port Kelang for running some of the fuel oil analysis.

\section{REFERENCES}

1. Zheng, J.L., 2007. Bio-oil from fast pyrolysis of rice husk: Yields and related properties and improvement of the pyrolysis system. J. Anal. Applied Pyrol., 80: 30-35. DOI: 10.1016/J.JAAP.2006.12.030

2. Economics and Industry Development Division, MPOB, 2008. Malaysian Oil palm Statistics 2007. 27th Edn., MPOB Publisher.

3. Das, P. and A. Ganesh, 2004. Bio-oil from pyrolysis of cashew nut shell-a near fuel. Biomass Bioenergy, 27: 265-275. DOI: 10.1016/S09619534(02)00182-4

4. Abdullah, N. and H. Gerhauser, 2008. Bio-oil derived from empty fruit bunches. Fuel, 87: 2606-2613. DOI: 10.1016/j.fuel.2008.02.011

5. Bridgwater, A.V. and G.V.C. Peacocke, 2000. Fast pyrolysis processes for biomass. Renew. Sustain. Energy Rev., 4: 1-73. DOI: 10.1016/S13640321(99)00007-6

6. Khor, K.H. and K.O. Lim, 2008. Slow pyrolysis of oil palm EFB. Int. Energy J., 9: 181-188.

7. Khor, K.H., Puad Elham and K.O. Lim, 2007. Slow pyrolysis of oil palm EFB using a pilot kiln. Proceeding of the Paper Presented in OPTUC, Nov. 13-15, Petaling Jaya.
8. Zin Zawawi, Z. and A.N. Ma, 1995. Management of palm oil mills-towards zero waste. Proceeding of the PORIM National Oil Palm ConferenceTechnologies in Plantation-The Way Forward, July 11-12, PORIM Publisher, Bangi, pp: 208-216.

9. Chew, K.S. and K.H. Tan, 2006. Conversion of bioresource (Oil palm EFB) into energy: State of the art. Proceeding of the 4th Seminar on Energy from Biomass, July 25-26, FRIM Publisher, Kepong, pp: 115-122.

10. Tsai, W.T., M.K. Lee and Y.M. Chang, 2006. Fast pyrolysis of rice straw, sugarcane bagasse and coconut shell in an induction-heating reactor. $\mathrm{J}$. Anal. Applied Pyrol., 76: 230-237. DOI: 10.1016/j.jaap.2005.11.007

11. Zheng, J.L. W.M. Yi and N.N. Wang, 2008. Biooil production from cotton stalk. Energy Conver. Manage., 49: 1724-1730. DOI: 10.1016/j.enconman.2007.11.005

12. Sipilaè, K., E. Kuoppala, L. Fagernaès and A. Oasmaa 1998. Characterization of biomass-based flash pyrolysis oil. Biomass Bioenergy, 14: 103-113. DOI: 10.1016/S0961-9534(97)10024-1

13. Michio Ikura, Maria Stanciulescu and Ed Hogan, 2003. Emulsification of pyrolysis derived bio-oil in diesel fuel. Biomass Bioenergy, 24: 221-232. DOI: 10.1016/S0140-6701(03)82808-4

14. Chiaramonti, D., M. Bonini, E. Fratini, G. Tondi, K. Gartner, A.V. Bridgwater, H.P. Grimm, I. Soldaini, A. Webster and P. Baglioni, 2003. Development of emulsions from biomass pyrolysis liquid and diesel and their use in engines-Part 1: Emulsion production. Biomass Bioenergy, 25: 85-99. DOI: 10.1016/S0140-6701(04)91616-5 